\title{
Letters
}

Website: www.bmj.com

Email: letters@bmj.com

\section{Protecting children from armed conflict}

Children affected by war must not be stigmatised as permanently damaged

EdiTor-Southall and Abbasi quote Unicef when they state that the psychological consequences of armed conflict on children are so great that they can rarely be repaired. ${ }^{1}$ Unicef indeed says that "time does not heal trauma," but there is no sound empirical basis for a generalisation that risks stigmatising whole populations of children affected by war as sick or permanently damaged. Even child survivors of Auschwitz did not turn out like this as a general rule, and there are no published studies of children from non-Western war zones to support such a conlusion.

Unicef and other agencies need to review such claims and costly interventions based on them; the claims owe more to prevailing sociocultural assumptions in the West than anything else. Over the past 50 years psychological explanations for life events and the medicalisation of distress have grown hugely. Because many people believe, for example, that rape or other criminal violence, childhood abuse, or even persistent bullying at school is an experience that may have lifelong psychological effects it seems unthinkable that war and atrocity should not do this to almost everyone

\section{Advice to authors}

We prefer to receive all responses electronically, sent either directly to our website or to the editorial office as email or on a disk. Processing your letter will be delayed unless it arrives in an electronic form.

We are now posting all direct submissions to our website within 72 hours of receipt and our intention is to post all other electronic submissions there as well. All responses will be eligible for publication in the paper journal.

Responses should be under 400 words and relate to articles published in the preceding month. They should include $\leqslant 5$ references, in the Vancouver style, including one to the BMJ article to which they relate. We welcome illustrations.

Please supply each author's current appointment and full address, and a phone or fax number or email address for the corresponding author. We ask authors to declare any competing interest.

Letters will be edited and may be shortened.

www.bmj.com

letters@bmj.com exposed to them. Constructions of "trauma" deployed in the health field are increasingly expansive and undiscriminating. ${ }^{2}$

No one wants to play down what children may suffer, or that war may produce clear psychological dysfunction in some (a minority). But it is not to their mental worlds but to their social worlds that survivors direct their attention, and humanitarian agencies should follow suit. The literature of both anthropology and mental health (in the case of mental health, starting with a classic study by Freud and Burling ham $^{3}$ ) shows the positive impact of family and community in buffering the short and longer term effects of war. The concept of child trauma is currently fashionable. But it is the social, cultural, and economic rebuilding of worlds shattered by war (including valued institutions such as schools), allied to urgent issues of equity and justice, which will determine the future wellbeing of severa million child survivors worldwide. ${ }^{4}$ For those for whom this does not happen war may indeed mean a life sentence, but this is not trauma.

Derek Summerfield Psychiatrist

Medical Foundation for the Care of Victims of Torture, London NW5 3EJ

1 Southall D, Abbasi K. Protecting children from armed conflict. BMJ 1998;316:1549-50. (23 May.)

2 Summerfield D. The psychological legacy of war and atrocity: the question of long-term and transgenerational effects and the need for a broad view. I Nerv Ment Dis 1996;184:375-7.

3 Freud A, Burlingham D. War and children. New York: Ernst Willard, 1943.

4 Summerfield D. Legacy of war: beyond "trauma" to the social fabric. Lancet 1997;349:1568.

Repaying debts takes precedence over health care in many Third World countries

EDITOR-Southall and Abbasi's editorial outlining the devastating effects of armed conflict on child health is welcome, as is the global perspective they encourage, but their call for aid budgets to be increased needs qualification. ${ }^{1}$ Repayment of debt by impoverished countries to the industrialised nations is greater than aid payments by a factor of three to one. Health budgets are being restricted in order to make these payments, under the direction of the International Monetary Fund. In Zimbabwe, for example, health spending per head has fallen by a third since the introduction of the structural adjustment programmes of the International Monetary Fund in $1990 .{ }^{2}$
Maternal mortality in Harare doubled in the two years after this.. In Uganda, for every pound per person spent on health care $£ 5.50$ is spent on debt repayments. ${ }^{4}$ It is estimated that 21 million children will die in developing countries before the millennium as a direct result of these policies. ${ }^{5}$

A rally of 60000 people, including many medical staff, gathered in Birmingham on 16 May to draw these facts to the attention of the G8 world leaders' summit. There was a cursory response from the political leaders and no change of policy.

Third World debt continues to have devastating effects on health. If targeted and controlled, aid programmes can be effective, but the crushing cycle of poverty will continue until politicians address the issue of debt in a meaningful way. The BMA can contribute by supporting the call by Jubilee 2000 (a coalition of development agencies) for debt relief and by encouraging its members to sign the petition which is gathering worldwide support; for more information contact Jubilee 2000, PO Box 100, London SE1 7RT (tel 0171401 9999).

C D Cooper Senior registrar in paediatric

Royal Manchester Children's Hospital, Manchester M27 1HA

j2000c@gn.apc.org

1 Southall D, Abbasi K. Protecting children from armed conflict. BMJ 1998;316:1549-51. (23 May.)

2 Oxfam. Policy document: a case for reform. Oxford: Oxfam, 1995 .

3 Chiviso M. Government spending on social services and the impact of structural adjustment in Zimbabwe. New York: Unicef, 1993.

4 Oxfam. Multilateral debt: the human costs. Oxford: Oxfam, 1996. (Oxfam international position paper.)

5 United Nations. United Nations development programme. New York: UN, 1997. (Human development report.)

Are most casualties non-combatants?

EdITOR-Southall and Abbasi's assertion that civilians account for nine tenths of casualties from recent conflicts is difficult to accept. ${ }^{1}$ Others making a similar contention provide references either to authors who have made the claim previously or to sources that make the claim without providing any methodology describing how the determination was made.

The International Committee of the Red Cross helps victims of armed conflict. This help can include surgical care, and a database recording information relating to the committee's surgical activities since 1991 contains data on over 28000 people, of whom 18831 have sustained weapons injuries.

The committee does not ask individuals to declare themselves as combatants or as non-combatants; sex and age are the only criteria by which one might estimate the 
proportion of non-combatant casualties from these data. An analysis of the first 17086 people admitted for weapons injuries reported that $35 \%$ were female; male and aged under 16 ; or male and aged $\geqslant 50 .{ }^{2}$ Clearly, this figure is a lower bound on the proportion of people with weapons injuries who are probably non-combatants and received care under the auspices of the Red Cross.

More important than the actual proportion of civilian casualties is the fact that this figure has been rising. ${ }^{3}$ In turn, this rise is associated with an increased incidence of low intensity conflict and an increasingly blurred border between insurgency and criminality. ${ }^{4}$ Complex factors and interests account for this, including the fundamental weakness of many states and the ease with which light weapons circulate throughout large parts of the world. ${ }^{5}$ It is the interplay of these determinants that merits consideration if one wishes to protect children and other civilians during armed conflict.

Southall and Abbasi point out that advocacy is a powerful tool available to the profession. But advocacy should be linked to credibility, and erroneous or exaggerated data can be used to undermine the validity of important messages and the trustworthiness of those who would bring them to the attention of the international community.

Attempts to study the events accompanying armed conflict have inherent limitations. One should approach these as in any other research context, controlling threats to internal and external validity as best one can and drawing conclusions without resorting to overstatement. The data, unfortunately, are bad enough that they speak for themselves.

David Meddings Epidemiologist

Health Operations Division, International

Committee of the Red Cross, 1202 Geneva,

Switzerland

1 Southall DP, Abbasi K. Protecting children from armed conflict. BMJ 1998;316:1549-50. (23 May.)

2 Coupland RM. The effects of weapons: defining superfluous injury and unnecessary suffering. Med Global Survival 1996;3:1-6

3 Garfield RM, Neugut AI. Epidemiologic analysis of warfare. A historical review. JAMA 1991;266:688-99.

4 Meddings DR. Weapons injuries during and after periods of conflict retrospective analysis. BMJ 1997:315:1417-20. 1997;315:1417-20. Smith C, Batchelor P, Potgieter J. Light weapons and the international arms trade. In: Small arms management and in association with the United Nations, 1996:1-59.

\section{Randomised controlled trial exists of levonorgestrel intrauterine system for menorrhagia}

EdITOR-We agree with Prentice's comments that the study by Lähteenmaki et al does not allow the conclusion that the levonorgestrel intrauterine system is an alternative to transcervical resection of endometrium. ${ }^{1}$ However, we were surprised that neither the study nor the commentary mentioned the recently published randomised controlled trial which compared the efficacy of the levonorgestrel intra- uterine system and transcervical resection of the endometrium in treating menorrhagia.

In this study women were randomly allocated to each treatment group and the main outcome measures were patient satisfaction rates and the reduction in menstrual loss (measured semiquantitatively) one year after treatment. The satisfaction rates (transcervical resection 94\% $v$ levonorgestrel $85 \% ; \mathrm{P}=0.26)$ and percentage reduction in menstrual scores $(89 \%$ v $79 \%$ $\mathrm{P}=0.015$ ) were comparable for the two treatments. On this basis, we can conclude that the levonorgestrel intrauterine system is a reasonable alternative to transcervical resection of the endometrium bearing in mind its added advantages of requiring only a simple outpatient procedure, contraceptive effect, and reversibility. However, technological advances have led to new methods of surgical endometrial ablation that can be used on an outpatient basis, ${ }^{3}$ which may in future reduce the advantages of the intrauterine system.

Amaju Ikomi Senior registrar

Nutan Gupta Registrar

Department of Obstetrics and Gynaecology,

St Peter's Hospital, Chertsey, Surrey KT16 0PZ

1 Lähteenmaki P, Haukkamaa M, Puolakka J, Riikonen U, Sainio S, SuvisaariJ, etal Open, Pandomised study of use of evonorgestrel releasing intrauterine system as alternative to hysterectomy. [With comn

1998;316:1122-6. (11 April.)

Crosignani PG, Vercellini P, Mosconi P, Oldani S, Cortesi De Giorgi O. Levonorgestrel releasing intrauterine device versus hysteroscopic endometrial resection in the treatment of dysfunctional uterine bleeding. Obstet Gynaeco 1997;90:257-63.

3 Singer A, Almanza R, Gutierrez A, Haber G, Bolduc LR, Neuwirth R. Preliminary clinical experience with a therma balloon endometrial ablation method to treat menorrhagia. Obstet Gynaecol 1994;83:732-4.

\section{Clarification of comments on trial of aminosidine in visceral leishmaniasis}

EDITOR-We would like to clarify five points in relation to Lockwood's commentary on our randomised controlled trial of aminosidine (paromomycin) for treating visceral leishmaniasis in Bihar, India.

Patients being screened for possible inclusion in the study were tested for HIV infection; all of the 120 patients included were negative for HIV. None of the patients tested (around 500) proved to be positive for HIV.

Audiometry was performed before starting treatment and then weekly during treatment and also on days 30, 90, and 180 of follow up in patients with ototoxicity; one such patient had severe (grade III) impairment that was still present at the end of follow up.

The use of single agent aminosidine as first line treatment may indeed give rise to the emergence of parasite resistance, as was the case with antimony. Its use must therefore be strictly monitored for efficacy and toxicity when the product is approved for this indication. In addition, the World Health Organisation Special Programme for Research and Training in Tropical
Diseases (TDR) has also conducted studies on combinations of aminosidine with antimony in Patna, Bihar. One of these trials is published, ${ }^{2}$ and the analyses of another study are under way. Although the combined treatment seems to show no advantage over aminosidine alone in terms of efficacy, tolerability, or cost, the combination should in theory mutually protect both drugs against resistance.

Although the cost of the sodium antimoniate produced in India is around $\$ 16$-24 per adult treatment, the products available elsewhere cost $\$ 120$-150 per treatment. ${ }^{3}$ Although TDR-WHO does not yet have an agreement for manufacturing aminosidine for leishmaniasis, its cost is expected not to exceed $\$ 50$ per treatment and will be the same the world over-and it may even be substantially less.

P Olliaro Manager, steering committee on drugs for malaria (CHEMAL)

UNDP/World Bank/WHO Special Programme for Research and Training in Tropical Diseases, Geneva, Switzerland

T K Jha Medical director

Kala-Azar Research Centre Muzaffarpur, Bihar, India

1 Jha TK, Olliaro P, Thakur CPN, Kanyok TP, Singhania BL, Singh IJ, et al. Comparative controlled trial of aminosidine visceral leishmaniasis in North Bihar, India [with commentary by DNJ Lockwood]. BMJ 1998:316:1200-5. (18 April.)

2 Thakur CP, Bhowmick S, Dolfi L, Olliaro P. Aminosidine plus sodium stibogluconate for the treatment of Indian plus sodium stibogluconate for the treatment of Indian Soc Trop Med Hyg 1995;88:219-23.

3 World Health Organisation, Overseas Development Administration. Manual on visceral leishmaniasis control. Administration. Manual on visceral leishma
Geneva: WHO, 1996. (WHO/LEISH/96.40.)

\section{Attention deficit hyperactivity disorder in children}

\section{Child psychiatrists should help parents} with difficult children, not blame them

EDITOR-Kewley reviews the current poor service provision and professional understanding of the group of disorders subsumed by the diagnostic category "attention deficit hyperactivity disorder." suggests in her accompanying commentary that the current nosological status of the disorder ignores important aetiological factors.

Her notion-that some underlying unspecified early emotional trauma is responsible for core symptoms of attention deficit hyperactivity disorder-must be challenged. As Kewley points out, the accumulating evidence that the disorder is primarily a genetically determined neurodevelopmental condition is extremely convincing. Orford's view that early abuse and trauma later manifest as symptoms and that the detection of these symptoms in children clearly illustrates early trauma is a prime example of the logical fallacy that underpins all psychoanalytical theory and practice. There is no convincing empirical evidence to support her assertion that psychoanalytical psychotherapy is often effective since it addresses the original emotionally traumatic experience. In sharp contrast, as Kewley 
states, the evidence base for the efficacy of psychostimulant treatment in moderate to severe forms of attention deficit hyperactivity disorder is beyond any reasonable doubt. Moreover, this treatment can help to make more effective other modalities of treatment that by themselves are usually ineffective (family therapy, individual psychotherapy, and special educational provision).

Theory and practice derived from psychoanalysis have been extremely influential in child psychiatric training until the recent adoption of evidence based practices. This fact has helped to explain why many families with children who have attention deficit hyperactivity disorder still experience so much difficulty in finding child psychiatrists who can actually help them rather than effectively blame them for their children's extreme difficulties. My recent survey finding that nearly half of Britain's child psychiatrists do not use psychostimulant treatment in their current practice shows that there is still a pressing need to improve standards of care in this area. ${ }^{2}$

David Bramble Senior lecturer in child and adolescent psychiatry

Department of Child and Adolescent Psychiatry, Nottingham University School of Medicine, Nottingham NG7 2UH

1 Kewley GD. Personal paper: Attention deficit hyperactivity disorder is underdiagnosed and undertreated in Britain [With commentary by E Orford.] BMJ 1998:316:1594-6. [With com

2 Bramble D. Psychostimulants and British child psychiatrists. Child Psychol Psychiatry Rev 1997;2:159-62.

\section{Benefits of adding other forms of treatment to medication remain unclear}

EDITOR-We need evidence to support the efficacy of combination treatment for attention deficit hyperactivity disorder. Kewley, in his paper on the disorder, concludes that drugs have an essential role when combined with educational, psychological, and other strategies as appropriate. ${ }^{1}$ This reflects the prevailing consensus among clinicians, but it is important to bear in mind the sparseness of evidence in the literature to support the efficacy of adding other modalities of treatment to drugs. Some research has shown a relative benefit in combining psychological and behavioural strategies with drug treatment, ${ }^{2}$ but other research has found no added benefit, ${ }^{3}$ and several experimental studies point to the major effect in combined interventions arising from the medical rather than the psychological and behavioural component. ${ }^{2}$

We have recently completed a systematic review of the evidence of the efficacy of stimulant drugs in relation to each other, and in relation to psychological and behavioural treatment and combined forms of treatment for children and youths with attention deficit hyperactivity disorder. ${ }^{5}$ Some of the obstacles in the literature facing those who would like to base treatment decisions on research evidence include the relative paucity of intervention studies other than studies of drug treatment and heterogeneity of various kinds that exist in the literature in relation to the disorder and its treatment, particularly in subject selection, control conditions, specific interventions, and the choice of outcome measures. The need for standards in intervention studies in attention deficit hyperactivity disorder and for carefully controlled prospective studies is clear. From the current published literature, there is abundant evidence of the clinical efficacy of psychostimulant drugs in controlling the core symptoms of the disorder and normalising behaviour, but the relative benefits of adding other modalities of treatment to drug treatment for the disorder remain unclear.

Anne Klassen Postdoctoral research fellow Parminder Raina Assistant professor

Anton Miller Clinical associate professor Shoo Lee Director

Faculty of Medicine, University of British Columbia, Vancouver, British Columbia V6H 3V4, Canada

1 Kewley GD. Personal paper: Attention deficit hyperactivity disorder is underdiagnosed and undertreated in Britain. With commentary by E Orford] $B M J$ 1998:316:1594-6. (23 May)

2 Gittelman R, Abikoff H, Pollack E, Klein DF, Katz S, Matte G. A controlled trial of behavior modifications and methylphenida in hyper , eds. Hyperadive children: the social ecology of identifica Beress, 1980:221-46.

3 Abikoff H. An evaluation of cognitive behavior therapy for hyperactive children. Adv Clin Child Psychol 1987;10:171

4 Pelham WE, Carlson C, Sams S, Vallano G, Dixon M], Hoza B. Separate and combined effects of methylphenidate and behavior modifications on boys with attention deficit-hyperactivity disorder in the classroom. J Consult Clin Psychol 1993;61:506-15.

5 Klassen A, Miller AR, Lee SK, Raina P, Olsen L. Relative efficacy of interventions for attention-deficit/hyperactivity disorder: can meta-analysis help? Pediatr Res 1998:43:13A.

\section{Danger is one of overdiagnosis}

EDITOR-Kewley's paper on attention deficit hyperactivity disorder is misleading and inaccurate. ${ }^{1}$ It exemplifies an increasingly used approach to diagnosis and treatment of psychiatric disorders in childhood. Hyperkinetic disorder is a clinical diagnosis based on current and past biopsychosocia factors. It is not and should not be reduced to a count of symptoms made from a checklist. In the absence of objective tests, the symptom cluster of impulsivity, inattention, and hyperactivity needs to be subjected to differential diagnosis in the time honoured medical tradition. The lack of mention of causes of inattentive and hyperactive behaviour other than attention deficit hyperactivity disorder is a major failing of the paper. Early traumatic experiences, attachment disorders, current abuse, neglect, and maternal depression can lead to symptoms of attention deficit hyperactivity disorder as all clinicians know. ${ }^{2}$ By ignoring the history, current experiences, and other psychosocial factors the paper takes the problem out of context and chooses a cookbook approach to diagnosis and treatment of childhood problems that is risky and dangerous.

In the case of attention deficit hyperactivity disorder there are dangers in extrapolating from epidemiological studies. These surveys rely on checklists of symptoms and rating scales to make a diagnosis of the disorder. Tests of attention have consistently failed to show appreciable impairment of attention. These studies ignore past experiences of the child and current psychosocial factors. Overreliance on symptom clusters leads inevitably to overestimation of prevalence. Studies that depend exclusively on rating scales have reported rates as high as $15 \%$. Hence care has to be exercised when conclusions are made on the basis of such estimates. Blind application of ICD-10 or DSM-IV criteria to a group of children in the care system, for example, is bound to produce high prevalence. I wonder whether the overzealous exponents of attention deficit hyperactivity disorder would treat these children with early trauma with stimulants.

Little evidence of specific brain dysfunction has been shown in children with the disorder. Functional brain imaging studies have been on small samples, and experts in the field have been cautious in their interpretation. ${ }^{3}$ It seems disingenuous to refer to one's own book written for parents to support the idea of brain dysfunction. The question of what is being inherited, a trait or a disorder, is open to debate.

Most child psychiatrists in the United Kingdom would agree that hyperkinetic disorder is a small subgroup within the syndromal definition of attention deficit hyperactivity disorder and that children with this tightly defined disorder may need treatment with stimulants after other conditions have been excluded. The real danger at the moment is the attempt to broaden the definition, diagnose the condition using symptom checklists and rating scales to the exclusion of psychosocial factors, and treat it with drugs. This would be the equivalent of calling all four legged animals with a tail donkeys.

M S Thambirajah Consultant child and adolescent psychiatrist

Child and Family Consultation Centre, Foundation NHS Trust, Stafford ST16 1PD

\section{Kewley GD. Attention deficit hyperactivity disorder is underdiagnosed and undertreated in Britain. [With com- mentary by E Orford.] BMJ 1998;716:1594-5. (23 May.) \\ 2 Haddad P, Garralda ME. Hyperkinetic syndrome and disruptive early experiences. Br J Psychiatry 1992;161. $700-3$ \\ 3 Tannock R. Attention deficit hyperactivity disorder: advances in cognitive, neurobiological and genetic research.J Child Psychol Psychiatry 1998;39:65-9.}

\section{Multidisciplinary approach to management is needed}

EditoR-Kewley's paper on attention deficit hyperactivity disorder and Orford's response seemed to reflect the age old debate about biological versus psychological factors in mental illness. ${ }^{1}$ Kewley asserts that attention deficit hyperactivity disorder is a genetic, inherited condition and cites carefully selected articles to support his belief that it is caused by brain dysfunction. In her commentary Orford's argument is that forgetfulness and poor concentration in a child can result from several causes, many of them psychological. She is critical of the current diagnostic criteria as being simply a list of symptoms, forgetting perhaps that our understanding of sickness has traditionally developed from categorising ill health in such a way.

Kewley has overstated his case. Evidence from twin studies that attention deficit 
hyperactivity disorder has a genetic component does not mean that it is inherited in all cases. An almost identical clinical picture can be found in children who have had disruptive early experiences. ${ }^{2}$ A more realistic theory is that the disorder is multifactorial; in some cases biological and genetic factors seem relevant whereas in others psychosocial issues are paramount. In the future it may even be necessary to refer to a range of attention deficit disorders once aetiological mechanisms are more clearly understood.

Drug treatment can be very effective but this does not necessarily imply that it is needed in all cases. More importantly, perhaps, there is as yet no evidence that treating the symptoms with stimulants reduces the likelihood of conduct disorder in adolescence or adult life. ${ }^{3}$ Kewley also dismisses psychosocial approaches as being equivalent to blaming the parents despite the fact that counselling for parents, educational advice, and behavioural therapy are valuable aspects of a comprehensive treatment package.

The child mental health team in which I work is, like many others, seeing increasing referrals of "possible attention deficit disorder." We regularly meet parents who have read books on the subject or downloaded information from relevant websites. I would therefore hesitate to suggest to my colleagues that the disorder is underdiagnosed and undertreated. The parents, struggling to manage a child with difficult behaviour, are hoping that we will automatically prescribe drugs. Many of them are surprised when we inform them that methylphenidate is an amphetamine. Our response to the demand has been to provide a comprehensive assessment supplemented by the use of detailed questionnaires. ${ }^{4}$ We look for biological, psychological, and environmental precipitants and offer several interventions including drugs. Orford emphasises the need for a greater refinement of the diagnostic criteria. I believe that a multidisciplinary, multiagency approach to assessment and management is even more important

Andrew Weaver Consultant in child and adolescent psychiatry

Child and Adolescent Mental Health Service,

Macclesfield District General Hospital, Macclesfield, Cheshire SK10 3BL

1 Kewley GD. Personal paper: Attention deficit hyperactivity disorder is underdiagnosed and undertreated in Britain. [With commentary by E Orford.] BMJ 1998;316:1594-6. (23 May $)$

2 Haddad PM, Garralda ME. Hyperkinetic syndrome and disruptive early experiences. Br J Psychiatry 1992;161: $700-3$

3 Barkley RA, Fischer M, Edelbrock CS, Smallish L. The adolescent outcome of hyperactive children diagnosed by research criteria: an 8 year prospective follow up study. JAm Acad Child Adolesc Psychiatry 1990;29:546-57.

4 Achenbach TM. Manual for the child behavior checklist. Burlington, VT: University of Vermont Department of Psychiatry, 1991.

\section{Author's reply}

EDITOR-Bramble's survey compares with the findings of my 1993 study - of lack of recognition of the condition and consequent underprescribing by child care professionals.

Klassen et al emphasise the importance of drug treatment. In Britain, however, evidence based management is hampered by a predominantly psychosocial approach. Symptoms must be viewed in the context of impairment, not just an epidemiological cut off point. Common late diagnosis with progressive comorbidity requires multiple interventions

Thambirajah erroneously equates hyperkinetic disorder with attention defici hyperactivity disorder. The wide variation and complexity require experienced comprehensive multiprofessional assessment not reliance on checklists or questionnaires

Haddad and Garralda's article quoted by Thambirajah and Weaver to substantiate that early traumatic experiences cause symptoms is anecdotal and unscientific. Literature showing that early traumatic experiences cause-rather than aggravate-core symptoms is sparse. Most such studies do not consider attention deficit hyperactivity disorder. My own book contains an extensive research bibliography.

The real danger is not carefully broadening the definition. Many children's difficulties are currently overlooked. Research indicates that impulsiveness-not hyperkinesis-is the key problem in the disorder. Thambirajah correctly asserts that the disorder is heterogeneous. Clinical experience shows that conduct disorder can be medically treated. Awaiting all the answers should not prevent treatment

Although inattentiveness is a trait in the normal population, this and other symptoms of attention deficit hyperactivity disorder can cause severe impairment Thambirajah and Weaver's comments underappreciate the difficulty and distress caused Often psychosocial approaches focus solely on presumed psychoanalytic reasons connected with parenting or emotions. These approaches are ineffective without an awareness of the condition. Twin studies support a strong genetic basis to attention deficit hyperactivity disorder, ${ }^{1}$ with environmental factors contributing little. A multidisciplinary approach ignoring biological issues is unhelpful and cost ineffective. Weaver's comment that he informs parents that methylphenidate is an amphetamine is alarming. Methylphenidate is a sympathomimetic amine with no evidence of long term addiction. ${ }^{2}$ Children with untreated attention deficit hyperactivity and conduct disorder are more prone to substance misuse."

At the Royal College of Physicians in 1902 George Still urged recognition of a group of children with possible biological deficit of moral control and behavioural inhibition. ${ }^{4}$ Psychosocial and psychoanalytical interventions in the United Kingdom have heavily influenced approaches since. Bias and ignorance allow patchy provision of unsatisfactory services. A government inquiry is needed to provide evidence based guidelines for the medical profession, education services, psychologists, and social services.

Geoffrey D Kewley Consultant paediatrician Learning Assessment Centre, Horsham, West Sussex RH12 2PD
1 Barkley RA. Gene linked to ADHD verified. The ADHD Report 1998;6:1-5.

2 Rosenberg D, Holttum J, Gershon S. Textbook for pharmacotherapy for child and adolescent psychiatric disorders. New York Brunner/Mazel, 1994

3 Biederman J, Faraone S, Mick E, Faraone SV, Weber W, Curtis S, et al. Is ADHD a risk factor for psychoactive substance abuse disorders? J Am Acad Child Adolesc Psychiatry 1997;36:21-9.

4 Still GF. The Goulstonian lectures on some abnormal psychical conditions in childhood. Lectures 1,2 \& 3. Lancet 1902;1:1008-12;1077-82;1163-68.

\section{Cholestanol and survival with simvastatin}

\section{More data are needed}

EDITOR-Miettinen and colleagues identify a subgroup of Finnish patients with high cholestanol ratios who gained no benefit from statin treatment. ${ }^{1}$ They suggest that such patients have a low rate of cholesterol synthesis but a high rate of cholesterol absorption and that drugs that block the synthesis of cholesterol therefore do not improve survival.

Surprisingly, they presented no data on the falls in serum cholesterol concentrations observed with simvastatin treatment within each cholestanol quarter. This information is essential to fully understand the link between high cholestanol ratio and the smaller reduction in relative risk with simvastatin. It would also be interesting to know whether the balance between cholesterol absorption and synthesis as measured by the cholestanol ratio accounts for a big part of the variability between patients in the response of serum cholesterol concentrations to simvastatin.

The authors do not comment on the relatively low $(21 \%)$ relative risk reduction by simvastatin in the Finnish patients. This seems much smaller than the 34\% risk reduction seen in all patients in the Scandinavian simvastatin survival study. ${ }^{2}$ Is this due to the different definition of major coronary events used in this analysis or did Finnish patients do less well than those in other countries?

E J Wallis Research assistan

R Williamson Lecturer

L E Ramsay Professor

W W Yeo Senior lecturer

P R Jackson Reader

Department of Clinical Pharmacology and

Therapeutics, Royal Hallamshire Hospital, Sheffield S10 2JF

1 Miettinen TA, Gylling H, Strandberg T, Sarna S for the Finnish 4S Investigators. Baseline serum cholestanol as predictor of recurrent coronary events in subgroup of Scandinavian simvastatin survival study. BMJ 1998;316: 1127-30. (11 April.)

2 Scandinavian Simvastatin Survival Study Group. Randomised trial of cholesterol lowering in 4444 patients with coronary heart disease; the Scandinavian simvastatin survival study (4S). Lancet 1994:344:1383-9.

\section{Authors' reply}

EDITOR-In our study the baseline serum cholestanol:cholesterol ratio was not related to the respective concentration of serum cholesterol. However, the ratio was significantly related to the serum cholesterol concentration of the survivors at six weeks $(\mathrm{P}<0.001)$ and five years $(\mathrm{P}<0.05)$ in the 
simvastatin group but not in the placebo group. This suggests that the higher the baseline cholestanol ratio the higher the serum cholesterol concentration was during treatment with simvastatin.

In addition, the decrease in serum cholesterol concentration produced by simvastatin was significantly related to the baseline cholestanol ratio at six weeks $(\mathrm{P}<0.01)$ when the dose of simvastatin was increased in about a third of the subjects. Inhibition of cholesterol synthesis by simvastatin, indicated by the presence in serum of precursor sterols of cholesterol, gradually decreased in survivors from the lowest to highest basal cholestanol quarters over the five to six years of treatment. Thus, the absolute decrease of lathosterol/cholesterol ratio caused by simvastatin was about two times higher $(\mathrm{P}<0.001)$ in the survivors in the lowest cholestanol quarter at baseline than in survivors in the highest quarter. The findings support our original suggestion that simvastatin lowers cholesterol synthesis and subsequently serum cholesterol concentrations less effectively in subjects with the high proportions of cholestanol than in those with the low proportions.

The smaller reduction of risk with simvastatin in our subjects compared with the overall results for the whole study group may be due to different major coronary events and different baseline population. Our population had a relatively large number of patients with angina alone.

Tatu A Miettinen Professor of medicine

Helena Gylling Senior lecturer

Timo Strandberg Assistant professor

Department of Medicine, University of Helsinki,

PO Box 340, FIN-00029 HYKS, Helsinki, Finland

Seppo Sarna Associate professor

Department of Public Health, University of Helsinki

\section{Cholesterol lowering diets and coronary heart disease}

\section{Advice should now be to increase intake of vegetable oils and fish}

EDITOR-The systematic review by Tang et al analysed the effect of various diets, particularly the American Heart Association step 1 and step 2 diets, on reducing total blood cholesterol concentration. ${ }^{1}$ Overall, the effect of diet on blood cholesterol concentrations in free-living communities was no more than about $6 \%$, with step 1 diets achieving a 3\% reduction and diets that increase the ratio of polyunsaturated to saturated fatty acids around an $8 \%$ fall.

The effect of diet on coronary heart disease rates is complementary. ${ }^{2}$ In six primary prevention trials of low fat and low cholesterol diets the odds ratio for death from coronary heart disease was 1.04 (95\% confidence interval 0.43 to 2.06) and for non-fatal events 1.05 (0.46 to 2.98 ); in two secondary prevention trials with a similar regimen the respective odds ratios were 1.21 (0.66 to 1.78 ) and 1.00 (0.76 to 1.37 ).

Four secondary prevention trials increased the ratio of polyunsaturated to saturated fats above 1.0 by using vegetable oils; plasma cholesterol concentrations decreased by a mean of $12.5 \%$. The odds ratio for death from coronary heart disease was $0.79(0.48$ to 1.20$)$ and for non-fatal events 0.72 ( 0.50 to 1.28$)$. This benefit may not be exclusively due to the high ratio since other risk factors were also controlled in some of these trials.

Some diets reduce the risk of coronary heart disease without changing plasma lipoprotein concentrations, as illustrated by two trials using supplementation of $n-3$ fats. ${ }^{3}$ The larger trial using fish showed an odds ratio of 0.71 for death from coronary heart disease and 0.84 for events but no reduction in plasma cholesterol concentration. ${ }^{3}$ The other used a margarine based on rape seed and a low cholesterol intake-odds ratios were less than 0.3 and 0.24 respectively without altering plasma lipoprotein concentrations. ${ }^{4}$ This beneficial effect may result from a decreased risk of thrombosis.

As implied by Tang et al, simple low fat and low cholesterol diets do not reduce plasma cholesterol concentration sufficiently to reduce the risk of coronary heart disease. The likely effectiveness of such diets was mainly based on simulation models. The facts are otherwise, ${ }^{5}$ perhaps because of poor compliance or concurrent reduction in plasma high density lipoprotein concentrations.

Dietary advice for the prevention of coronary heart disease should now recommend increasing the intake of vegetable oils, particularly olive oil, and fish to increase the ratio of polyunsaturated to saturated fatty acids to 1.0 or more.

M F Oliver Professor emeritus

Cardiac Medicine, National Heart and Lung Institute, London SW3 6LY

1 Tang JL, Armitage JM, Lancaster T, Silagy CA, Fowler GH, Neil HAW. Systematic review of dietary intervention trial to lower blood total cholesterol in free-living subjects. $B M$ J 1998;316:1213-9. (18 April.)

2 Oliver MF. It is more important to increase the intake of unsaturated fats than to decrease the intake of saturated fats: evidence from clinical trials relating to ischemic heart disease. Am J Clin Nutr 1997;66:980-6S.

3 Burr ML, Fehily AM, Gilbert JF, Rogers S, Holliday RM, Sweetnam PM, et al. Effects of changes in fat, fish, and fibre intakes on death and myocardial reinfarction: diet and reinfarction trial (DART). Lancet 1989;ii:757-61.

4 De Lorgeril M, Renaud S, Mamelle N, Salen P, Martin J-I, De Lorgeril M, R Monjaud I, et al. Mediterranean alpha-linolenic acid-ric diet in secondary prevent

5 Holme I. Relation of coronary heart disease incidence and 5 Holne l. Relation of coronary heart disease incidence an tat plasma cholesterol reduction in randomised trials: use of meta-analysis. Br Heart

\section{Dietary advice should focus on}

promoting antioxidants and the right sort of fats

EDIToR-The meta-analysis by Tang et al showed that dietary changes produced an average fall of only $5.3 \%$ in blood cholesterol concentration even in patients with coronary heart disease, who would be expected to be well motivated to comply with advice. ${ }^{1}$ Let us contrast this with the effects of qualitative dietary changes after a myocardial infarction.

The diet and reinfarction trial from South Wales in over 2000 men recovering from a myocardial infarction showed that a modest intake of oily fish (and fish oil capsules in those unable to tolerate oily fish) resulted in a 29\% reduction in total mortality during the first two years after a myocardial infarction, although there was no significant change in total plasma cholesterol concentration. ${ }^{2}$ The same study found no evidence of benefit from the conventional high fibre and low saturated fat diets.

A subsequent study showed that a diet high in fruit, vegetables, and nuts reduced cardiac events by $16 \%$ compared with the standard low fat diet. ${ }^{3}$ The latest evidence from France again confirms the benefits of a Mediterranean diet, which is high in antioxidants, vitamins, oleic acid, and n-3 fatty acids. ${ }^{4}$ The trial was halted early owing to an extraordinary $73 \%$ reduction in major cardiac events in patients recovering from a myocardial infarction.

Assuming that a finite amount of time is available for dietary counselling, doctors would do better to use that time to encourage their patients to consume oily fish, use olive oil or rape seed oil (or margarines manufactured from these oils), eat lots of fruit and vegetables, avoid animal fats, and drink in moderation. Patients are more likely to comply with this advice. Droning on about low fat diets in the vague hope of patients revolutionising their diet and reducing their cholesterol concentration is unlikely to work. In secondary prevention the best treatment for hyperlipidaemia is a statin. Dietary advice does help, but its best effect is seen when it is focused on promoting antioxidants and the right sort of fats.

Advising patients to eat more oily fish after a myocardial infarction is among the most effective interventions doctors can make. $^{5}$

Shaun Conway General practitioner

Hingham Surgery, Norfolk NR9 4JB

1 Tang JL, Armitage JM, Lancaster T, Silagy CA, Fowler GH, Neil HAW Systematic review of dietary intervention trial to lower blood total cholesterol in free-living subjects. $B M$ 1998:316:1213-9. (18 April)

2 Burr ML, Fehily AM, Gilbert JF, Rogers S, Holliday RM, Sw ML, Fenily AM, Gilbert JP, Rogers S, Holliay RM, Sweetnam PM, et al. Eflects of changes in fat, fish, and fibre .

3 Singh RM, Rastogi SS, Verma R, Laxmi B, Singh R, Ghosh $\mathrm{S}$, et al. Randomised trial of cardioprotective diet in patients with recent acute myocardial infarction: results of 1 year follow up. BMJ 1992;304:1015-9.

4 De Lorgeril M, Salen P, Caillat-Vallet E, Hanauer MT, Barthelemy JC, Mamelle N. Control of bias in dietary trial to prevent coronary recurrences: the Lyon diet heart study. Eur J Clin Nutr 1997;51:116-22.

5 Conway S, Fuller L, Jesudason K, Lipp A, Morrison J, Page $\mathrm{AJF}$, et al. Guidelines in the secondary prevention of coronary heart disease. Norwich: East Norfolk Health Authority, 1998.

\section{Single dose of anti-D immunoglobulin for antenatal prophylaxis is smaller in the Netherlands than in the United Kingdom}

EDITOR-Lee is right in correcting my editorial on dose schedules of anti-D immunoglobulin for antenatal prophylaxis. ${ }^{12}$ The Edinburgh consensus conference agreed on two main options-a dose of $500 \mathrm{IU}$ at 28 
and 34 weeks' gestation or "alternatively a single larger dose early in the trimester," but the size of the larger dose was not mentioned. ${ }^{3}$ It is usually accepted to be 1500 IU at 28-30 weeks, when a single dose is chosen instead of two smaller doses. In my editorial I unintentionally mentioned the Dutch policy of antenatal prophylaxis that was started this year. Anti-D immunoglobulin from volunteer Dutch blood donors (CLB Sanquin Blood Supply Foundation, Amsterdam) comes only in vials of $1000 \mathrm{IU}$ (apart from a mini-dose of $375 \mathrm{IU}$, which is used for early abortion). This dose has been used in the Netherlands since the introduction of postnatal prophylaxis in 1969. To avoid a third dose of $1500 \mathrm{IU}$ and undoubtedly the introduction of administrative failures, an antenatal programme was chosen that advocates the use of $1000 \mathrm{IU}$ at 30 weeks of pregnancy. At birth the same dose is given. To my knowledge, this is the first policy of its kind, and it might be a way of saving the scarce resource of anti-D immunoglobulin from volunteer blood donors. A national evaluation programme was set up concomitantly to monitor the effects of the Dutch programme.

Bob van Dijk Consultant in transfusion medicine SeroConsult, 9752 EV 19, Haren, Netherlands

1 Lee D. Preventing RhD haemolytic disease of the newborn. BMJ 1998;316:1611. (23 May.)

2 Van Dijk B. Preventing RhD haemolytic disease of the newborn. BMJ 1997;315:1480-1.

3 Royal College of Physicians of Edinburgh and Royal College of Obstetricians and Gynaecologists. Consensus conference on anti-D prophylaxis, 7-8 April 1997. $\mathrm{Br}$ Haematol 1997:97:997-8.

\section{EU doctors get caught in training trap}

EDITOR-The specialist medical order is a national law implementing the European directive $93 / 16$, which regulates postgraduate training; it came into effect on 16 January 1996. The Specialist Training Authority is now the government body designed by law to grant certificates of completion of specialist training.

Before the implementation of directive 93/16 the General Medical Council granted a certificate of specialist training to those applicants from the European Union who had satisfied the minimum requirements concerning employment and examinations in the United Kingdom. Regrettably, no provision was made for doctors who were still in training at the time the law was modified, and no grace period was established to allow trainees who had begun training under the previous system to conclude their certification according to the previous rules.

To rectify this situation, representatives of the profession, the General Medical Council, and the Specialist Training Authority agreed that a certificate of training in the United Kingdom would be provided to doctors from the European Union caught between the requirements of the old and new systems. The Commission of Senior Officials of Public Health, in its regular meetings in Brussels, agreed to recognise these doctors' training and grant them the same status as had been granted to holders of a certificate of specialist training under the former regulations.

Because this certificate is not explicitly mentioned in European directive 93/16 many doctors in the European Union encounter difficulties in having it recognised by other European countries. The number of European doctors training in the United Kingdom after their basic medical qualification has increased dramatically in the past few years, and the number who have complained about this situation to the General Medical Council, Specialist Training Authority, and BMA is high.

The BMA is to be commended for its role in seeking a satisfactory solution. But the involvement of the BMA is not enough: individual doctors affected by this awkward situation must seek each other out and, together, devise a plan of action for contacting the appropriate bodies of the European Union as well as national governments.

Andrea Perinti Ophthalmic trainee at Siena University

Via S Pietro, 2453100 Siena, Italy mailto:perinti@unisi.it

\section{Corrections}

Effects of the Heartbeat Wales programme

An error occurred in this letter by Ebrahim and Davey-Smith (26 September). The penultimate paragraph should have read as follows. Two responses to rigorous evaluations that showed little or no added value of health promotion programmes for cardiovascular disease have been the design and execution of potentially misleading and methodologically flawed studies, ${ }^{4}$ for which exorbitant claims are made. ${ }^{5} \mathrm{~A}$ third response has been the suggestion that rigorous evaluative methods are not appropriate in this situation.

\section{Antiretroviral combination therapy and HIV} infection

Two errors occurred in this letter by McMenamin et al (26 September 1998;887). The name of one of the participants in the study is Tamiza Parpia, not Parpira. She is a statistician, not a researcher.

\section{Cost effectiveness of community leg ulcer clinics}

Owing to an editorial error during processing a letter by Franks and Moffat that had been published on 14 March 1998 was used again as the penultimate letter in this cluster (17 October 1998:1079-81). The correct letter is published below.

\section{Sensitivity of tools used may explain} difference in results between studies

EDITOR-Morrell et al presented evidence from a randomised trial that supported the use of community clinics in patients being treated for chronic leg ulceration. ${ }^{1}$ After the success of the Riverside project ${ }^{2}$ we have helped several community trusts to implement similar services. Evidence from these audits are in agreement with the trial in some ways but different in others.

Although we in Riverside achieved a healing rate of $69 \%$ after 12 weeks of treatment, ${ }^{2}$ subsequent changes in the service have resulted in more modest benefits. Before implementation of the new service an audit of 519 patients showed a baseline healing rate at 12 weeks of just $15 \%$, which improved after implementation to $41 \%$ in an audit of 438 patients. After adjustment for the known risk factors of ulcer size, ulcer duration, mobility, and ankle movement ${ }^{3}$ healing rates improved to $20 \%$ before implementation and to $56 \%$ after implementation. ${ }^{4}$

Our results show lower costs of treatment after implementation, principally through reduced nurse time. We are surprised at the large difference in unit costs of treatment between the clinic (£29.90) and a home visit $(£ 10.60) .{ }^{1}$ Our results indicate that the mean cost per visit before implementation was £19.35. In our studies mean cost per visit was similar in both phases, but there was a considerable reduction in frequency of visits after implementation (19.0 v 11.7 per 12 week cycle) (World Congress of Phlebology, Sydney, September 1998).

The other most notable difference between our results and those of Morrell et al concerns patients' perceived health. Using the Nottingham health profile we have consistently shown improvements after effective treatment in both observational studies and trials. The difference between our results and those of Morrell et al may be due to the sensitivity of the tools being used or the longer duration of the trial compared with our audits. The initial benefits noted by patients in the short term may be counterbalanced by the long term deterioration in this elderly population.

The challenge to clinicians is now developing evidence based services. The results from our work suggest that effective implementation can be achieved by trusts to improve clinical and patient outcomes while reducing costs.

Peter J Franks Co-director

Christine J Moffatt Professor of nursing

Centre for Research and Implementation of

Clinical Practice, Thames Valley University, Wolfson Institute of Health Sciences, London W5 2BS

\footnotetext{
1 Morrell CJ, Walters SJ, Dixon S, Collins KA, Brereton LML Peters J, et al. Cost effectiveness of community leg ulcer Peters J, et al. Cost effectiveness of community leg ulcer
clinics: randomised controlled trial. BMJ 1998:316:148791. (16 May)

2 Moffatt CJ, Franks PJ, Oldroyd MI, Bosanquet N, Brown P, Greenhalgh RM, et al. Community clinics for leg ulcers and impact on healing. BMJ 1992;305:1389-92.

3 Franks PJ, Moffatt CJ, Connolly M, Bosanquet N, Oldroyd MI, Greenhalgh RM, et al. Factors associated with healing leg ulceration with high compression. Age Ageing 1995;24:407-10

4 Franks PJ, Moffatt CJ. Leg ulcer healing rates: multivariate models to adjust for risk factors for healing [abstract]. Br J Dermatol 1997;136:286.
} 